Estudios Románicos, Volumen 29, 2020, pp. 209-222

ISSN: 0210-4911

eISSN: $1989-614 \mathrm{X}$

DOI: https://doi.org/10.6018/ER.377941

\title{
RETROSPECTIVA SINTÁCTICO-SEMÁNTICA DEL ADJETIVO FRANCÉS II: DE LAS GRAMÁTICAS TRADICIONALES A OTROS ESTUDIOS CONTEMPORÁNEOS
}

(Syntactic-semantic retrospective of the French adjective II: from traditional grammars to other contemporary studies)

\author{
Aránzazu Gil Casadomet* \\ Universidad Autónoma de Madrid
}

\begin{abstract}
After a first review of the French adjective from Antiquity to the traditional grammars in Syntactic-semantic retrospective of the French adjective I, this second article presents a continuation of the retrospective throughout the 20th and 21 th centuries. Different grammatical works define, classify and exemplify the French adjective from different syntactic and semantic points of view, paying special attention to the types of adjectives and their functions in the sentence.
\end{abstract}

Keywords: Adjective; French language; Retrospective; Historical-theoretical context; Syntax; Semantics.

Resumen: Tras una primera revisión del adjetivo francés desde la Antigüedad a las gramáticas tradicionales en Retrospectiva sintáctico-semántica del adjetivo francés $I$, este segundo artículo presenta una continuidad del estudio a lo largo de los siglos XX y XXI. Diferentes trabajos gramaticales definen, clasifican y ejemplifican el adjetivo francés desde varios puntos de vista sintácticos y semánticos, prestando especial atención a las especies de los adjetivos y sus funciones en la oración.

Palabras clave: Adjetivo; Lengua francesa; Retrospectiva; Contexto históricoteórico; Sintaxis; Semántica.

\footnotetext{
* Dirección para correspondencia: Aránzazu Gil Casadomet. Departamento de Filología Francesa. Facultad de Filosofía y Letras. Universidad Autónoma de Madrid. Campus de Cantoblanco. 28049 Madrid (aranzazu.gil@uam.es)
} 


\section{Introducción}

Este artículo completa un estudio histórico-teórico del adjetivo francés cuya primera parte puede consultarse en Retrospectiva sintáctico-semántica del adjetivo francés I: de la Antigüedad a las gramáticas tradicionales. En esta primera parte, expusimos cómo gramáticos y estudiosos de la lengua francesa han descrito el adjetivo desde aspectos sintáctico-semánticos desde el latín hasta el francés moderno. Comprobamos en sus obras una tendencia generalizada hacia la importancia de catalogar el adjetivo como parte del discurso, dentro de la clase verbal o de la clase nominal, o de estudiarlo desde la noción de determinación, sin prestar atención a otras particularidades del mismo como pueden ser sus funciones sintácticas, cuestión largamente discutida a partir de las gramáticas tradicionales y hasta nuestros días. En la Antigüedad, el adjetivo es descrito como un constituyente de la clase verbal que forma parte del rhêna (Platón 2008: 195-254, 1866-1868). Es más tarde, entre los siglos I a.C. y V d.C. que comenzamos a ver una relación más próxima entre el nom y el adjectif en las gramáticas de Dionisio de Tracia (s. I a.C.) y Prisciano (s. V d.C.). Esta relación se comprende porque el adjetivo empieza a describirse para indicar una cualidad o cantidad de las sustancias y es aquí donde observamos una primera pincelada semántica que aporta significado a la descripción léxica de los adjetivos. En la Edad Media, encontramos de forma generalizada la distinción entre sustantivo y adjetivo como dos clases principales del nombre (Hélie, s. XII) y en el Renacimiento, el adjetivo empieza a tener su lugar como parte del discurso disgregada del nombre (Maupas, 1607) junto con otras partes como noms, pronoms, verbes, participes y adverbes. Sin embargo, esta división no tuvo gran acogida a la luz de las clasificaciones que aportan otros gramáticos entre los siglos XVII y XVIII como por ejemplo Chiflet (1659), Arnauld y Lancelot (1666), Buffier (1709), RégnierDesmarais (1706), Restaut (1730), Wailly (1747), Girard (1747) y Du Marsais (1797), en cuyas gramáticas y estudios de corte gramatical el adjetivo sigue perteneciendo a la clase del nombre. Será a partir del siglo XVII cuando el adjetivo es finalmente considerado como un elemento no inscrito en la categoría del nombre (Beauzée 1767).

Se hace más hincapié a partir de esta época en la descripción del adjetivo desde una óptica semántica: tal y como ya reflejaba Meigret (1550) los adjetivos expresan la calidad o la cantidad del alma o del cuerpo. En esta línea, Beauzée (1767) diferencia entre adjetivos físicos (calificativos y relacionales) y metafísicos (determinativos). En gramáticas publicadas posteriormente, los esfuerzos por catalogar el adjetivo siguen esta postura, es decir, se muestra más interés en estudiar la noción de determinación, así como la división de los adjetivos no determinativos en calificativos y relacionales y sus diferencias con los adjetivos determinativos (Lhomond 1780; Girault-Duvivier 1811; Bonneau y Lucan 1839). Asimismo, es curioso cómo Bonnot de Condillac nombra a los adjetivos resultantes de esta división: "les adjectifs qui déterminent, les adjectifs qui développent" (1821: 440), los primeros son los llamados tradicionalmente como determinantes porque tal y como indica el nombre determinan al sustantivo con el cual forma el sintagma nominal, y los segundos llamados calificativos porque en su 
Retrospectiva sintáctico-semántica del adjetivo francés II:

De las gramáticas tradicionales a otros estudios contemporáneos

significado desarrollan, proyectan, complementan una idea residente en el sustantivo al que acompañan.

Al final del período en el que nacen las gramáticas tradicionales, empezamos a ver un tratamiento nuevo del adjetivo, esta vez no desde una perspectiva como parte del discurso sino como función sintáctica de la palabra. Bonnot de Condillac (1821) y Noël y Chapsal (1823) describen el adjetivo desde su funcionalidad como atributo, y es aquí donde el artículo presente continúa con el estudio sobre el adjetivo, en una transición desde las gramáticas tradicionales hasta otros estudios contemporáneos de corte gramatical, centrando nuestro punto de mira en varios aspectos sintáctico-semánticos en los que ya está establecida de manera general la concepción del adjetivo como parte del discurso disgregada del nombre.

En esta segunda parte, el contenido que hemos consultado de las gramáticas y de otros estudios de corte gramatical ${ }^{1}$ se resume a las especies del adjetivo y sus funciones en la oración en una rigurosa síntesis, aunque no exhaustiva, tomando el adjetivo como el objeto principal de nuestra observación. Veremos la postura de varios gramáticos, filósofos y lingüistas a la hora de enumerar los diferentes tipos de adjetivos según pares dicotómicos como los adjetivos calificativos y los no calificativos, también llamados determinantes, o los adjetivos calificativos y los relaciones, entre otros. Además, expondremos cómo las funciones del adjetivo en esta nueva etapa se delimitan principalmente según dos aspectos, la primera y más conocida: el adjetivo como epiteto y, la segunda: el adjetivo como atributo. A finales del siglo XX y a principios del siglo XXI, ambas funciones han destacado por encima de otras como la de adjetivo en aposición. Mostraremos que es un aspecto determinante en la concepción descriptiva del adjetivo puesto que ha sido tratado durante siglos desde una óptica principalmente morfosintáctica, y recientemente con más relevancia desde su función sintáctica, aportando trazos importantes al significado de los adjetivos.

Entre las obras seleccionadas para proseguir con el análisis durante los siglos XX y XXI, hemos consultado La grammaire des fautes (1929) de Henri Frei, Des mots à la pensé, Essai de grammaire de la langue française (1911-1934)² de Jacques Damourette et Édourad Pichon, Le Bon Usage (1936-2011) y Précis de Grammaire Française (19391992) de Maurice Grevisse ${ }^{3}$, Précis de syntaxe du français contemporain (1947) de

1 La escuela que engloba principalmente la mayoría de las obras consultadas es de carácter estructuralista, decisión que nos hemos obligado a tomar con el fin de acotar los resultados del estudio de un centenar de gramáticas escogidas.

2 La aparición de las dos fechas entre paréntesis tiene su explicación. La que se encuentra a la izquierda del guion data de la primera publicación y la que aparece a la derecha, de la última publicación registrada según el ISBN de la obra.

3 En el caso de Le Bon Usage (LBU), hemos consultado Grevisse (1936 [1955]: 258-360, 1993: 820-857), la segunda versión que hemos utilizado corresponde al trabajo continuado desde mediados del siglo XX por el gramático belga André Goosse. Hemos considerado oportuno revisar diferentes versiones de $L B U$ a lo largo de los siglos XX y XXI atendiendo a las diversas modificaciones que pudiésemos encontrar. Las ediciones de 1955 y 1969 no varían en el contenido relacionado con el adjetivo, y las versiones de 1993 y 2008, refundadas por A. Goosse, tampoco varían entre sí sino con las dos primeras versiones señaladas. En el caso del Précis de Grammaire Française (PGF), hemos consultado Grevisse (1939 [1992]: 82-110). 
Walther Wartburg y Paul Zumthor, Éléments de syntaxe structurale (1959) de Lucien Tesnière, Grammaire du Français classique et moderne (1962-1993) de Robert-Léon Wagner y Jacqueline Pinchon ${ }^{4}$, Grammaire Larousse du français contemporain (1964) de Jean-Claude Chevalier et al., La pensée et la langue (1965) de Ferdinand Brunot, Grammaire structurale du français moderne (1970) de Georges Galichet, Syntaxe du français moderne: ses fondements historiques et psychologiques (1971) de Georges Le Bidois y Robert Le Bidois, La nouvelle grammaire du français (1973) de Jean Dubois y René Lagane, Précis historique de grammaire française (1974) de Knud Togeby, ...Et il fallut apprendre à écrire à tous les petits Français, histoire de la grammaire scolaire (1977) de André Chervel, Code du français courant (1984) de Henri Bonnard, L'adjectif attribut (1985) de Martin Riegel, la Grammaire de la Phrase Française (1993) de Pierre le Goffic, Syntaxe du français moderne et contemporain (1993) de Hervé Bechade, la Grammaire méthodique du français (1994-2014) de Martin Riegel, Jean-Christophe Pellat y René Rioul $^{5}$, Pour enseigner la grammaire (1996) de Roberte Tomassone, Grammaire critique du français (1997-2010) de Marc Wilmet ${ }^{6}, L^{\prime}$ adjectif (1999) de Jan Goes y L'adjectif en français (1999) de Michèle Noailly.

\section{El adjetivo francés en gramáticas y otros estudios de los siglos XX y XXI: especial atención a las especies y sus funciones}

\subsection{Adjetivos calificativos y adjetivos determinativos}

A lo largo de los siglos XX y XXI, encontramos una importante cantidad de trabajos dedicados al adjetivo, ya sean gramáticas u otros estudios de corte gramatical en los que se presta atención a las especies del adjetivo y su función sintáctica, así como otros autores van más allá en la descripción de estas propiedades y aportan conocimientos semánticos relacionados con el adjetivo. En las obras consultadas, hemos podido contemplar una tendencia generalizada en el tratamiento del adjetivo sobre el significado del adjetivo y lo que expresa, ya sea una cualidad o una cantidad de un ser o de un objeto a los que describe y acompaña. En $L B U$ (1936), PLF (1939), Riegel et al. (1994), Wilmet (1997) y Noailly (1999) se sigue haciendo referencia de forma notoria a la relación inherente entre lo que expresa un adjetivo y el substantivo al que acompaña, tal y como observábamos en otras gramáticas publicadas en siglos precedentes como por ejemplo Dionisio de Tracia (s. I a.C.), Prisciano (s. V d.C.), (Hélie, s. XII), Meigret (1550) o Beauzée (1767), entre otras. En versiones posteriores de $L B U$, la entrada adjetivo es apreciada de la siguiente forma:

$4 \quad C f$. Wagner y Pinchon (1962 [1991]: 129-163). Esta paginación corresponde al capítulo que presenta el adjetivo calificativo. Para conocer la clasificación y sus diferencias de los determinantes específicos y complementarios del sustantivo que también responden al título de adjetivo como por ejemplo los adjetivos posesivos, demostrativos, numerales, indefinidos, interrogativos o exclamativos, vide pp. 83-126.

5 Esta gramática data de 1994, sin embargo nos hemos servido de la tercera edición publicada en 2001 (pp. 355-368).

$6 \quad$ Nos hemos servido de la edición de 2003 (pp. 101-117) para este estudio. 
L'adjectif est un mot qui varie en genre et en nombre, genre et nombre qu'il reçoit par le phénomène de l'accord, du nom (parfois du pronom) auquel il se rapporte. (LBU 1993: 820, 2008: 701)

Esta relación está intrínsecamente conectada con la noción de determinación y la posterior división tradicional del adjetivo en calificativos y determinantes que podemos apreciar más claramente a partir de mediados del siglo XVIII en la Grammaire générale de Beauzée (1767). Así, en muchas otras obras ( $L B U$ 1936; PGF 1939; Wartburg y Zumthor 1947; Wagner \& Jacqueline 1962; Wilmet 1997; Noailly 1999) encontramos esta separación nacida de la determinación, es decir, de la separación entre aquellos adjetivos que se emplean para calificar y otros para indicar cantidad, posesión, demostración, etc. (Bonneau y Lucan 1839) ${ }^{7}$. En la entrada dedicada al adjetivo en el $L B U$, el gramático belga Maurice Grevisse (1895-1980) expone:

L'adjectif est un mot que l'on joint au nom pour exprimer une qualité de l'être ou de l'objet nommé ou pour introduire ce nom dans le discours. [...] On distingue deux espèces d'adjectifs : l'adjectif qualificatif et l'adjectif non qualificatif (ce dernier appelé traditionnellement « adjectif déterminatif «. [...] L'adjectif qualificatif est celui qui exprime une manière d'être, une qualité de l'être ou de l'objet désigné par le nom auquel il est joint: Un livre utile. Un ouvrier actif. (LBU 1955: 258-259)

La cita permite entender que el adjetivo, o bien califica al nombre o bien lo determina, como lo expresa igualmente la lingüista francesa Michèle Noailly en L'adjectif en français: «Un adjectif quand il s'adjoint à un premier nom recteur, ou bien le qualifie, ou bien le détermine» (1999: 189).

En cuanto a los adjetivos calificativos, los gramáticos Martin Riegel, Jean-Christophe Pellat y René Rioul proponen que:

Les qualificatifs indiquent une caractéristique, essentielle ou contingente ( $U n$ homme irasciblelfurieux), du terme auquel ils se rapportent : forme, dimension, couleur, etc., [et] ils renvoient à des propriétés, c'est-à-dire à des concepts exclusivement descriptifs dépourvus d'autonomie référentielle (Riegel et al. 2001: 355-356).

Los autores explican que el adjetivo calificativo se interpreta a través de las propiedades o conceptos a los que es reenviado. Asimismo, los adjetivos calificativos no pueden, como hacen los nombres, determinar directamente las ocurrencias particulares, sino que un adjetivo en una frase viene señalado en relación con la entidad que caracteriza -C'est un fleuve profond $/ *$ c'est un profond $^{\mathbb{B}}$. Sin embargo, los adjetivos determinantes, según Wilmet (1997), describen el objeto desde el exterior y, a su vez, se dividen en

7 Por el contrario, ciertas gramáticas no hacen distinción en la importancia de uso del aspecto calificativo frente al determinativo, o del aspecto epíteto frente al atributo; nos referimos a Moignet (1981), Frontier (1997), Aslanides (2001) y Baylon y Fabre (1973).

8 La segunda ocurrencia del adjetivo profond no está bien empleada, transgrediendo las reglas sintácticas de uso, de ahí el indicador *. 
numerales cardinales y ordinales, posesivos tónicos o átonos, demostrativos, relativos, interrogativos-exclamativos e indefinidos:

(1) Un camion roule à $90 \mathrm{~km} / \mathrm{h}$ (numeral cardinal).

(2) La première fois, elle est allée à Barcelone (numeral ordinal).

(3) Nous parlons de nos affaires (posesivo átono).

(4) Parlons des affaires à nous (posesivo tónico).

(5) Cette maison est grande (demostrativo).

(6) Les témoins, lesquels l'accusation appelle, ne sont pas présents (relativo).

(7) Quelle surprise! (exclamativo)

(8) Quelques étudiants n'ont pas passé l'épreuve (indefinido).

Otros secundan esta división, tales como Galichet (1970), G. Le Bidois y R. Le Bidois (1971), Dubois y Lagane (1973) y Bonnard (1984) que coinciden en la separación del adjetivo de la clase del nombre y además, diferencian claramente el adjetivo calificativo de los no calificativos (posesivos, demostrativos, indefinidos, etc.) caracterizados por una extensión relacional y referencial.

Sin embargo, en el capítulo de "L’adjectif qualificatif", los gramáticos franceses Robert-Léon Wagner y Jacqueline Pinchon exponen que los adjetivos calificativos también pueden determinar. Entre las construcciones gramaticales portadoras de caracterización, hallamos adjetivos calificativos pospuestos al término que determinan -Une ville maritime-, complementos adnominales - La ville aux cents tours - , una proposición relativa -Je lui rappelai un café qui nous était familier-o un sustantivo construido directamente, siempre pospuesto al término que determina - La Ville lumière-.

El lingüista danés Knud Togeby, por su parte, describe en su obra Précis historique de grammaire française (1974) la tendencia en francés moderno, que ya existía en latín, de anteponer al nombre los adjetivos elementales como grand, petit, vieux, jeune, bon, mauvais, beau, etc. y posponer los adjetivos objetivos que indican espacio, tiempo, dimensiones físicas, clasificaciones y colores. En cambio, deja en una categoría mixta los adjetivos subjetivos que tienen valores como bête, précieux, fin, terrible, dur, plein, etc. (1974: 70-89).

En otras gramáticas, como en el $P G F$, se propone un tercer tipo de adjetivos llamado adjectifs verbaux. Grevisse distingue entre los adjetivos calificativos, los no calificativos y los adjetivos verbales. Los adjetivos calificativos expresan una manera de ser, una cualidad del ser humano u objeto designado por el nombre al que se adjuntan - Un ouvier actif-. Los no calificativos son numerales, posesivos, demostrativos, relativos, interrogativos, exclamativos e indefinidos. Y los adjetivos verbales son los participios presentes empleados como adjetivos - La brise errante-.

\subsection{Adjetivos calificativos y adjetivos de relación}

Entre las especies del adjetivo, encontramos otra oposición tradicional entre estas gramáticas que atañe al adjetivo calificativo frente al adjetivo relacional. La 
oposición entre adjetivos calificativos y relacionales nos reenvía a la distinción que el gramático suizo Henri Frei (1929) hace entre el término inherencia y el de relación, respectivamente. La inherencia genera un vínculo existente entre una sustancia y su cualidad -Une jolie rose- y la relación entre dos sustancias externas la una a la otra -Boucherie chevaline-. Leemos también en Riegel et al. (1994) que éstos últimos se encuentran inmediatamente pospuestos al nombre porque indican una relación con el referente del nombre del cual derivan. Esta relación depende del semantismo de su nombre receptor -La race chevaline es la raza de los caballos-. Por extensión, explican que constituyen el equivalente sintáctico y semántico de un complemento del nombre o una proposición relativa que explicitarían esta relación -Un objet métallique está hecho de metal-. Además, en el caso en el que los adjetivos no denoten propiedades, no se asocian a un nombre de propiedad -L'autorité paternelle/*la paternité de l'autoritéy no se coordinan con los adjetivos calificativos -*Un parc immense et municipal $^{2}$ Sin embargo, los autores concretizan que pueden funcionar como atributos en empleo contrastivo-Ce parc n'est pas national, mais régional-.

Encontramos en la obra de otro autor (Tesnière 1959) una referencia a ciertos adjetivos llamados también de relación, si bien no corresponde con la postura de Frei (1929) o Riegel et al. (1994). Tesnière da otra nomenclatura a los adjetivos determinantes y calificativos, diferencia los adjetivos generales -tel, mon- de los adjetivos particulares -blanc- respectivamente desde el punto de vista de la naturaleza misma de la idea abstracta que los adjetivos expresan. Entre los generales y los particulares, detalla una subclasificación en adjetivos atributos - Le livre rouge- $\mathrm{y}$ de relación - Ce livre- $\underline{-i}-$. Los adjetivos atributos, a su vez, son clasificados en adjetivos de calidad -Le livre rouge- $\mathrm{y}$ cantidad-Deux livres-. El autor añade lo siguiente en relación con estas clasificaciones:

Les adjectifs généraux sont ordinairement qualifiés dans la grammaire traditionnelle d'indéterminés ou indéfinis [...]. Les adjectifs particuliers ont une compréhension restreinte et d'ailleurs variable avec leur complexité sémantique. Elle est minimum dans un adjectif à sens simple tel que rouge. Elle est sensiblement plus vaste dans un adjectif à sens complexe tel que mièvre [...]. Les adjectifs de qualité particuliers sont ceux que la grammaire traditionnelle désigne ordinairement par le terme d'adjectifs qualificatifs. [...] Les adjectifs de quantité particuliers sont ceux que la grammaire traditionnelle désigne ordinairement par le terme d'adjectifs numéraux cardinaux : trois livres (Tesnière 1969: 68-69).

\subsection{Funciones del adjetivo: epíteto, atributo, aposición.}

Como último aspecto que queremos tratar en este artículo, vamos a destacar otra característica sintáctico-semántica del adjetivo francés estrechamente relacionada con la función en la oración. Wagner y Pinchon (1962) hacen hincapié en el adjetivo calificativo y diferencian entre sus funciones de epíteto y de atributo. Exponen que esta división tradicional es discutible porque se descuidan otras funciones del adjetivo

\footnotetext{
$9 \quad$ Immense es calificativo y municipal es relacional.
} 
desligado que asume roles como el de aposición o el de complemento determinativo. El adjetivo en función de epíteto se encuentra en la frase detrás del sustantivo que determina -L'oiseau noir dans le soleil levant-o delante, introduciéndose entre este y sus determinantes específicos -Il est certain que nos dernières relations avaient été d'une grande sécheresse-. Desde el punto de vista del sentido, el adjetivo epíteto evoca una cualidad concebida como consustancial a la persona o cosa que es designada por el sustantivo.

Tratándose del adjetivo en función de atributo, los autores afirman que el adjetivo forma parte de la frase donde se halla un juicio predicativo. Se evoca una cualidad que pertenece a una persona o cosa a la que se le atribuye. Además, estos gramáticos añaden que no solo los verbos de estado o atribución propiamente dichos como devenir, être, paraître, sembler, nommer o trouver pueden preceder adjetivos en función de atributo sino también los verbos de acción que impliquen el reconocimiento de una cualidad momentánea o durable del sujeto -Il a vécu pauvre-. Los adjetivos en función de atributo pueden aparecer también en la oración bajo una construcción indirecta. Se encuentran tras preposiciones como pour $-L a$ vie des forçats peut passer pour luxueuse comparée à celle des Sauviat-o por medio de comme o que -Distrait comme tu es; De quoi te mêles-tu, coquine, imprudente que tu es ?-, así como esta posición del adjetivo desligada del sustantivo o del pronombre al que hace referencia se encuentra separada por una coma o una forma verbal. Además, añaden que el adjetivo en aposición solo tiene valor descriptivo: sirve para caracterizar una actitud que determine al sustantivo y ponga de relieve una calificación al respecto -Les sapins, noirs, en étaient les gardiens funèbres-o poner en relación el adjetivo con un nombre propio o un pronombre-Fabrice, ivre de colère, arriva aussi à cette ligne de saules-. Es de considerar entonces que, tal y como se precisa en esta gramática, la función que el adjetivo asume en la oración está marcada por el lugar que este ocupa.

Otros autores añaden otra terminología a estos adjetivos, es el caso de $L B U$ (2008), Retomando las figuras subordinadas al sustantivo, se añade que el adjetivo puede presentarse en la oración como adjetivo epíteto o adjetivo atributo ${ }^{10}$. En el caso del primero, se trata de un adjetivo o participio verbal subordinado a un nombre o a un pronombre. Podemos apreciar en la obra la existencia de varios tipos de adjetivos epítetos, como los de relación, equivalentes a complementos nominales -Une grammaire grecque-. Así pues, se explica en el capítulo que los epítetos de transferencia son otro tipo de adjetivos epítetos que son transferidos de un nombre a otro de la misma familia léxica o mismo ámbito semántico -Maladie imaginaire, malade imaginaire-. Igualmente, se añade en la gramática que el adjetivo como atributo forma parte del predicado y en la proposición verbal está ligado o bien al sujeto por medio de un verbo cópula -La table est ovale- o bien al complemento directo a través de un verbo transitivo -Je crois l'affaire terminée-.

10 Los autores afirman oponer el epíteto a la aposición, siendo el primero un adjetivo o participio y el segundo un nombre (LBU 2008: 404). 
El atributo emplea la función llamada atributiva cuando se encuentra en posición satélite de un verbo siempre en relación a través de un sustantivo (Riegel 1985). Los verbos que lo acompañan pueden ser de carácter esencialmente atributivos como être o paraître, o bien ocasionalmente atributivos como juger o annoncer (Riegel et al. 2001: 235-241). Acompañan al adjetivo calificativo o al adjetivo relacional en posición ya sea como atributo del sujeto, ya sea como atributo del complemento directo. El epíteto, por su parte, caracteriza el adjetivo cuando éste se halla en posición satélite de un sustantivo -función de epíteto unido al sustantivo o desligado de este por comas en la frase-.

La estructura être + adjetivo es la estructura tipo que permite atribuir una cualidad, permanente u ocasional, a un sujeto. En Le Goffic (1993), se menciona que el verbo être funciona como un verbo cópula, estableciendo el lazo entre el nombre (sujeto) y el adjetivo (llamado atributo del sujeto). Esta unión queda marcada por la concordancia en género y número del adjetivo, teniendo como referencia o punto de partida el nombre -Marie est contente-. Además, el adjetivo atributo se sitúa normalmente pospuesto al verbo, pero ocasionalmente puede encontrarse antepuesto al mismo-Triste était mon âme-. Otros verbos aparecen en la oración seguidos por un adjetivo complementando el significado del sujeto gracias a una cualidad. Estos verbos son: devenir, tomber, sembler, paraître, faire y rester/demeurer. He aquí algunos ejemplos expuestos que hemos encontrado en Le Goffic (1993):

(9) Marie est devenue très jolie.

(10) Paul est tombé malade.

(11) Marie semble désorientée.

(12) Cette solution paraît préférable.

(13) Marie fait vieille pour son âge.

(14) Paul est resté (demeuré) très calme.

Entre ellos, el adjetivo funciona como atributo del sujeto. Otros verbos franceses que se utilizan acompañados de un adjetivo son naître, mourir, vivre, revenir, se promener, etc.:

(16) Ils vécurent heureux.

(17) Paul s'est marié trop jeune.

(18) Paul est mort pauvre.

(19) Paul est revenu de son stage complètement transformé.

(20) Mais ne te promène donc pas tout nue!

Estos verbos concebidos como copulativos guardan ciertas características semánticas comunes al verbo être cuando preceden a un adjetivo como complemento esencial que atribuye una cualidad al sujeto. Sin embargo, los adjetivos utilizados con verbos como devenir, tomber, naître o morir destacan por su carácter epíteto y no por una atribución permanente o instantánea al sujeto. De hecho, reflejan el hábito del ser humano 
de categorizar en la frase la experiencia en términos locativos del adjetivo. Esta característica nos ayuda a comprender las propiedades señaladas sobre el adjetivo epíteto como fenómeno de la anteposición de los adjetivos a los nombres en un grupo nominal como en Un petit regard. Describe el punto de vista del hablante sobre el objeto del discurso o el contenido nocional del sustantivo al que califica (Noailly 1999). Es por lo que se pueden delimitar las propiedades semánticas de los adjetivos a propósito de la organización de su lugar en la frase, así en Noailly (1999) se afirma que la anteposición del adjetivo epíteto es descriptiva -Une délicieuse soirée-, teniendo un valor distintivo entre sus características semánticas si se encuentra pospuesto -Une soirée délicieuse- $\mathrm{o}$ un comportamiento restrictivo - Un ballon ovale-, donde se califica en un nivel metalingüístico precisando el nivel de apropiación. Por lo tanto, con el fin de comprender otras posiciones de los adjetivos en la frase, se atribuye a todo el conjunto del contexto discursivo la responsabilidad de la interpretación atributiva que se desencadena de un adjetivo pospuesto. Los adjetivos constituyen un subdominio de primitivos semánticos del lenguaje ${ }^{11}$, cuyo rol referencial de base es el de describir las propiedades de los objetos y sucesos que los nombres y sustantivos determinan. Tal y como expone esta autora, en el caso del significado que se expande por la localización del adjetivo en la frase, todo adjetivo instaura una relación entre el referente del nombre al que acompaña y la categoría nombrada por el lexema a partir del cual se forma. Se trata de un fenómeno lingüístico de significado que posee influencia en el contexto en el que este significado puede ser sensible sintácticamente.

En otras gramáticas como las de Brunot (1965), Chevalier et al. (1964), Béchade (1993) y Tomassone (1996) hacen mayor hincapié en el adjetivo atributo del sujeto opuesto al del complemento. Afirman que el primero tiene un comportamiento sintáctico próximo a verbos como être, devenir, paraître, sembler, rester, demeurer, se conserver, se maintenir, se montrer, se révéler, se trouver, se sentir, avoir l>air, devenir, se faire, faire, tomber, subsister, naître, partir, vivre o estimer. El gramático Hervé Béchade propone una serie de ejemplos para algunos de estos verbos cópula:

(21) Je suis l'enfant de la vieillesse de mon père (J. Giono).

(22) De ma vie, je ne me suis senti tour à tour plus désarmé, plus faible, plus lâche sous l'injure (M. Jouhandeau).

(23) Kouriloff paraissait ravi de constater à quel point sa mémoire était restée fidèle (H. Troyat).

(24) Enfin le paysage devint rocheux, titanesque et féerique (A. Maurois).

(25) Et j'observai le corbeau. Mais il se tint immobile (A. de Saint-Exupéry).

En L'adjectif (1999) de Jean Goes, la función de atributo «constitue une notion charnière entre le monde du nom et celui du verbe» (1999: 107). El adjetivo posee la particularidad de poder aparecer solo como complemento, es decir sin que ni una

11 Hacemos referencia a conceptos transferidos a través de palabras clave o semas primeros, son aquellos conceptos susceptibles de ser irreductibles que funcionan como descriptores y son comunes en múltiples lenguas dotándoles así de un carácter universal (Wierzbicka 1993). 
preposición ni un determinante puedan introducirlo, no solamente en las construcciones con être, sino en todas las construcciones en las que están implicados los verbos llamados atributivos. En las estructuras Sintagma Nominal + être + Adjetivo, siempre se puede pronominalizar este último por un le invariable, indicio del atributo calificativo. Queda siempre como un complemento del verbo être y no como participio pasado de una forma compuesta - pretérito perfecto compuesto o pasiva-. Según el autor, la función de atributo otorga al adjetivo tres categorías semánticas diferentes que se dividen en la atribución de una propiedad, ligada principalmente a los adjetivos y más raramente a otras partes del discurso; la identificación, portadora de una noción calificativa expresada principalmente por grupos nominales; y la localización espacial, temporal o indicadora de materia, expresada sobre todo por grupos preposicionales. Así pues, el adjetivo es considerado como la parte del discurso prototípica para la función de atributo y la cópula transporta la función predicativa como verbo que es, mientras que el adjetivo transmite la mayor parte del semantismo de la frase.

\section{Conclusiones}

Los gramáticos y estudiosos de la lengua presentes en nuestro estudio siguen una descripción más o menos homogeneizada en relación con la descripción del adjetivo, sus formas, características y usos desde varios siglos antes de las gramáticas tradicionales y hasta nuestros días. Tras el análisis llevado a cabo y presentado a lo largo de los artículos Retrospectiva sintáctico-semántica del adjetivo francés I y II, podemos delimitar una línea temporal asociada a la concepción del adjetivo como parte del discurso y a las diferentes funciones con las que se han ido empleando en la oración.

Concluimos tras nuestro estudio que el adjetivo ha seguido una evolución notoria en la que ha sufrido cambios de pertenencia a clases gramaticales, al igual que se le ha diseminado y clasificado en varias especies teniendo en cuenta características de índole sintáctica y semántica. A lo largo de este recorrido, hemos observado varios estadios evolutivos del adjetivo que aquí resumimos: (1) en estudios que datan de la Antigüedad grecolatina, el adjetivo ha pasado de ser un constituyente del grupo verbal a forma parte del grupo nominal; (2) posteriormente, tal y como lo reflejan obras de la Edad Media, se le ha considerado asociado al grupo del nombre como nom adjectif, opuesto al nom substantif; (3) entre los siglos XVII y XVIII, se comienza a disociar el adjetivo del grupo del nombre y a ser parte del discurso independiente; (4) es también en esta época cuando empezamos a observar que los estudios del adjetivo se tildan de tonos semánticos, apareciendo características como la cualidad o la cantidad en su definición; (5) es bien entrado el siglo XVIII, cuando se conoce la subclasificación del adjetivo en calificativos y determinativos -o no calificativos- según la noción de determinación, así como en adjetivos verbales como tercera clasificación que se prolongará hasta nuestros días, con matices entre unos autores y otros, atendiendo de forma generalizada a esta cuestión; (5) en el siglo XIX, las descripciones y divisiones del adjetivo antes mencionadas ya forman parte del conocimiento y aceptación de los gramáticos, en esta época es el turno de otras clasificaciones del adjetivo como 
por ejemplo la dicotómica entre el adjetivo calificativo y el adjetivo relacional, según la noción de inherencia y relación relativas al propio adjetivo; (6) a finales de esta época, también se empiezan a hacer notables otras clasificaciones del adjetivo, esta vez desde un punto de vista funcional, así pues se trata el adjetivo desde su cualidad de atributo; (7) si bien, no será hasta el siglo XX cuando el atributo es estudiado en profundidad - tratado de adjetivo o participio verbal subordinado a un nombre o a un pronombre- en oposición al adjetivo epíteto -siendo estas categorías admisibles para describir a los adjetivos calificativos y relacionales- y al empleado en aposición como valor descriptivo.

Con esta retrospectiva, finalizamos un estudio a lo largo de diferentes épocas sobre el adjetivo en lengua francesa. Como dijimos no se trata de un trabajo exhaustivo en la medida en que los estudios sobre el adjetivo son numerosos y ricos en su contenido, sino en la presentación y exposición de un estudio elaborado que nació de la curiosidad por esta parte del discurso y su tratamiento desde diferentes consideraciones sintácticosemánticas.

\section{BIBLIOGRAFÍA}

ARNAULD, Antoine; LANCELOT, Claude (1666 [1960]): Grammaire générale et raisonnée. Stuttgart: Friedrich Frommann Verlag.

ARRIVÉ, Michel; CHEVALIER, Jean-Claude (1970): La grammaire. París: Éditions Klincksieck.

ASLANIDES, Sophie (2001): Grammaire du français du mot au texte. París: Honoré Champion.

BAYLON, Christian; FABRE, Paul (1973): Grammaire systématique de la langue française. París: Nathan.

BEAUZÉE, Nicholas (1767): Grammaire générale ou exposition raisonnée des éléments nécessaires du langage pour servir de fondement à l'étude de toutes les langues. París: Imprimerie de J. Barbou.

BÉCHADE, Hervé (1993): Syntaxe du français moderne et contemporain. París: PUF. BONNARD, Henri (1984): Code du français courant. París: Magnard.

BONNEAU, Jean-Marie; LUCAN (1839): La Grammaire selon l' Académie. París: Éditions Bonneau et Lucan.

BRUNOT, Ferdinand (1965): La pensée et la langue. París: Masson.

BUFFIER, Claude (1709): Grammaire française sur un plan nouveau. París: Nicolas Le Clerc et al.

CHERVEL, André (1977): ...Et il fallut apprendre à écrire à tous les petits Français, histoire de la grammaire scolaire. París: Payot.

(1982): Les grammaires (1800-1974): répertoire chronologique. París: INRP.

CHEVALIER, Jean-Claude (1994): Histoire de la grammaire française. París: PUF.

CHEVALIER, Jean-Claude et al. (1964): Grammaire Larousse du français contemporain. París: Larousse. 
CHIFLET, Laurent (1659 [1680]): Essay d'une parfaite grammaire de la langue française. Colonia: Pierre Le Grand.

CONDILLAC, Étienne Bonnot de (1821): Euvres complètes de Condillac. París: Lecointe et Durey, Tourneux, tomo VI.

DAMOURETTE, Jacques; PICHON, Édouard (1911-1934 [1935]): Des mots à la pensée, Essai de grammaire de la langue française. París: D'Artrey, tomo IV.

DIONISIO DE TRACIA (1989 [1998]): La grammaire de Denys le Thrace. Trad. y notas de Jean Lallot. París: CNRS Éditions, D.L.

DU MARSAIS, César Chesneau (1797 [1971]): Mélanges de Grammaire, de Philosophie, etc., tirés de l'Encyclopédie. Stuttgart: Friedrich Frommann Verlag.

DUBOIS, Jean; LAGANE, René. (1973): La nouvelle grammaire du français. París: Larousse.

FREI, Henri (1929): La grammaire des fautes. París: P. Geuthner.

FRONTIER, Alain (1997): La grammaire du français. París: Belin.

GALICHET, Georges (1970 [1973]): Grammaire structurale du français moderne. Montréal: Éditions Hurtubise.

GOES, Jean (1999): L'adjectif. Entre nom et verbe. París: Éditions Duculot.

GIRARD, A. Gabriel (1747): Vrais principes de la langue françoise. París: Le Breton.

GIRAULT-DUVIVIER, Charles-Pierre (1811 [1853]): Grammaire des Grammaires ou analyse raisonnée des meilleurs traités de la langue française. París: Jean-Michel Eberhart imprimeur.

GREVISSE, Maurice (1936): Le Bon Usage, Grammaire française. París: Éditions Duculot, 1955, 1969, 1993 y 2008 (las dos últimas refundadas por André Goosse).

(1939 [1992]): Précis de grammaire française. París: Éditions Duculot.

HÉLIE, Pierre (1993): Summa Super Priscianum, 113 de Studies and texts. Comentarios de Leo Reilly. Toronto: Pontifical Institute of Mediaeval Studies.

LE BIDOIS, Georges; LE BIDOIS, Robert (1971): Syntaxe du français moderne : ses fondements historiques et psychologiques. París: A. et J. Picard.

LE GOFFIC, Pierre (1993): Grammaire de la phrase française. París: Hachette.

LHOMOND, Ch. François (1780): Éléments de grammaire française. Quebec: J. A. Langlais.

LIVET, Ch. Louis (1859 [2001]): La grammaire française et les grammairiens du XVIe siècle. París: Didier et Cie.

MAUPAS, Charles (1607 [1632]): Grammaire et syntaxe francoise. Rouen: J. Cailloué.

MEIGRET, Louis (1550 [1970]): Le tretté de la grammere françoeze. Ginebra: Slatkine Reprints.

MOIGNET, Gérard (1981): Systématique de la langue française. París: Klinckssieck.

NOAILLY, Michèle (1999): L’adjectif en français. París: Ophrys.

NOËL, François J. M.; CHAPSAL, Charles P. (1823 [1870]): Nouvelle Grammaire française, Sur un plan très-méthodique, avec de nombreux exercices d'orthographe, de syntaxe et de ponctuation. París: Marie-Nyon Jeune. 
PLATÓN (1866-1868 [2008]): CEuvres complètes : Cratyle, Le Sophiste. París: Flammarion.

PRISCIANO (1515 [1550]): Institutiones Grammaticae. París: Iodoco Badio Ascensio. RÉGNIER-DESMARAIS, François-Séraphin (1706): Traité de la grammaire françoise. Ginebra: Slatkine.

RESTAUT, Pierre (1730): Principes généraux et raisonnes de la grammaire française. París: J. Desaint.

RIEGEL, Martin (1985): L'adjectif attribut. París: PUF.

RIEGEL, Martin et al. (1994 [2001]): Grammaire méthodique du français. París: PUF. SWIGGERS, Pierre (1984): Grammaire et méthode au XVIIIe siècle. Leuven: Peeters.

TELL, Julien (1967): Les grammairiens français (1520-1874). Ginebra: Slatkine Reprints.

TESNIÈRE, Lucien (1959 [1969]): Éléments de syntaxe structurale. París: Klincksieck. TOGEBY, Knud (1974): Précis historique de grammaire française. Copenhague: Akademisk Forlag.

TOMASSONE, Roberte (1996): Pour enseigner la grammaire. París: Delagrave.

WAGNER, Robert-Léon; PINCHON, Jacqueline (1991): Grammaire du français classique et moderne. París: Hachette.

WAILLY, N. François de (1747 [1826]): Principes généraux et particuliers de la langue françoise. París: Pierre Maumus.

WARTBURG, Walther; ZUMTHOR, Paul (1947): Précis de syntaxe du français contemporain. Berna: August Francke Verlag.

WIERZBICKA, Anna (1993): «La quête des primitifs sémantiques», Langue française. Les primitifs sémantiques. Vol. 98: 9-23.

WILMET, Marc (2003): Grammaire critique du français. Bruselas: Éditions Duculot.

\section{PERFIL ACADÉMICO Y PROFESIONAL}

Aránzazu Gil Casadomet ha realizado su tesis doctoral en lingüística argumentativa y enunciativa, en la Universidad Autónoma de Madrid. Actualmente, trabaja como Profesora Ayudante Doctora en el Departamento de Filología Francesa de esta misma universidad. Sus intereses científicos son múltiples y desarrolla sus trabajos de investigación en semántica argumentativa y enunciativa, lingüística computacional y lexicografía.

Fecha de recepción : 19/05/2019

Fecha de aceptación : 06/05/2020 